\title{
Topographic and Landcover Influence on Lower Atmospheric Profiles Measured by Small Unoccupied Aerial Systems (sUAS)
}

\author{
Elizabeth M. Prior ${ }^{1,2, *(\mathbb{D})}$, Gretchen R. Miller ${ }^{3}(\mathbb{D})$ and Kelly Brumbelow ${ }^{3}$ \\ 1 Department of Civil and Environmental Engineering, Auburn University, Auburn, AL 36849, USA \\ 2 Department of Biological Systems Engineering, Virginia Tech, Blacksburg, VA 24061, USA \\ Zachry Department of Civil and Environmental Engineering, Texas A\&M University, \\ College Station, TX 77843, USA; gmiller@civil.tamu.edu (G.R.M.); kbrumbelow@civil.tamu.edu (K.B.) \\ * Correspondence: eprior@vt.edu
}

\section{check for}

updates

Citation: Prior, E.M.; Miller, G.R.; Brumbelow, K. Topographic and Landcover Influence on Lower Atmospheric Profiles Measured by Small Unoccupied Aerial Systems (sUAS). Drones 2021, 5, 82. https:// doi.org/10.3390/drones5030082

Academic Editors: Pablo

Rodríguez-Gonzálvez, Peter Webley, Jack Elston, Richard Hann, Diego González-Aguilera and Jamey Jacob

Received: 20 July 2021

Accepted: 24 August 2021

Published: 26 August 2021

Publisher's Note: MDPI stays neutral with regard to jurisdictional claims in published maps and institutional affiliations.

Copyright: (c) 2021 by the authors. Licensee MDPI, Basel, Switzerland. This article is an open access article distributed under the terms and conditions of the Creative Commons Attribution (CC BY) license (https:/ / creativecommons.org/licenses/by/ $4.0 /)$.

\begin{abstract}
Small unoccupied aerial systems (sUASs) are increasingly being used for field data collection and remote sensing purposes. Their ease of use, ability to carry sensors, low cost, and precise maneuverability and navigation make them a versatile tool for a field researcher. Procedures and instrumentation for sUASs are largely undefined, especially for atmospheric and hydrologic applications. The sUAS's ability to collect atmospheric data for characterizing land-atmosphere interactions was examined at three distinct locations: Costa Rican rainforest, mountainous terrain in Georgia, USA, and land surfaces surrounding a lake in Florida, USA. This study aims to give further insight on rapid, sub-hourly changes in the planetary boundary layer and how land development alters land-atmosphere interactions. The methodology of using an sUAS for land-atmospheric remote sensing and data collection was developed and refined by considering sUAS wind downdraft influence and executing systematic flight patterns throughout the day. The sUAS was successful in gathering temperature and dew point data, including rapid variations due to changing weather conditions, at high spatial and temporal resolution over various land types, including water, forest, mountainous terrain, agriculture, and impermeable human-made surfaces. The procedure produced reliably consistent vertical profiles over small domains in space and time, validating the general approach. These findings suggest a healthy ability to diagnose land surface atmospheric interactions that influence the dynamic nature of the near-surface boundary layer.
\end{abstract}

Keywords: land-atmosphere interactions; planetary boundary layer; unmanned aerial vehicles; unoccupied aerial vehicles; vertical atmospheric profiles; biometeorology

\section{Introduction}

Small unoccupied aerial systems (sUASs) are beginning to offer researchers an unprecedented ability to observe atmospheric processes using a mobile platform. Powerful tools, weather balloons, aerial drop sondes, and fixed towers all present issues of logistics and representativeness when used for profiling in the lower atmosphere. Unlike these previous methods, sUASs are rapidly deployable, offer instantly reconfigurable flight plans, and can sense at spatial resolutions limited only by the accuracy of their GPS units. In this study, we demonstrate the use of an sUAS for depicting vertical trends in temperature and dew point within the planetary boundary layer (PBL), across rapid changes in landcover types and during events such as inversions. Such observations have been widely recognized by the scientific community as critical for improving Earth system models and predicting weather and climate changes [1,2].

The use of sUAS for meteorological data collection is currently in its infancy, but shows great potential for expansion. Elston et al. (2015) provide a thorough overview of meteorological applications using fixed-wing sUAS [3]. While these types of sUAS can typically carry a heavier and more sophisticated sensing payload, their characteristic flight patterns are more adept at gathering horizontally distributed data, as opposed 
to the vertical profiling for which rotocopter-style configurations are particularly adept. Notable exceptions are the M2AV Carolo [4], the SUMO [5,6], and the MASC-3 [7] which have both been flown in helical ascent patterns to gather temperature, humidity, wind and/or turbulence profiles. Others have addressed operational questions associated with atmospheric profiling, such as sampling scales [8], turbulence and mixing effects associated with rotors [9], and even public perception [10].

The recent LAPSE-RATE campaign [11] provided a comprehensive intercomparison of sUASs for meteorological applications, conducting a suite of test flights measuring pressure, temperature, relative humidity, and wind speeds for analysis against radiosonde and tower $(\sim 18 \mathrm{~m})$ data. Among the participants were the CopterSonde 2 [12], the Nimbus PTH sensor [13], and the MDASS system [14], all of which were associated with multirotor platforms and have previously been used in profile studies. The study established that such systems could reliably measure atmospheric profiles with minimal rotor outwash effects, but that anemometer placement and shielding and aspiration of temperature sensors were important.

For researchers, platform development and testing has been a priority to date. Thus, the use of sUASs for purely meteorological observations has thus been somewhat limited, and relatively few cross-site comparisons or campaigns over difficult terrain have been conducted. Notable among these are Brewer and Clements (2020) [15] who performed meteorological profiling over a prescribed burn to monitor the fire environment; Koch et al. (2018) [16] who evaluated the use of an sUAS for observing convection initiation processes in the planetary boundary layer; Nolan et al. (2018) [17] who characterized Lagrangian Coherent Structures occurring during LAPSE-RATE flights; and Lampert et al. (2020) [18] who investigated the atmospheric boundary layer over polar environments. Applications of sUASs for monitoring air pollution and particulates, rather than strictly weather phenomena, have been somewhat more developed [19-24]. The platforms used for such studies are typically more complex, but do include weather-sensing capabilities (e.g., ALADINA [25]).

The vision for the use of such systems is not lacking, however. For example, Leuenberger et al. (2020) [26] and the development of the Metodrone by Meteomatics (Meteomatics, St. Gallen, Switzerland) [27-29] make a strong case for use of automated sUASs to "fill an observational gap" of the planetary boundary layer that is needed to improve numerical weather models. Chilson et al. (2019) [30] further propose a 3-D Mesonet composed of automated weather-observing sUASs (WxUAS; [31]) to complement existing weather stations. Such a system is a "long-desired component to U.S. operational observing systems" with the ability to "measure vertical profiles of wind, temperature, and moisture in the lower troposphere at high spatial and temporal resolution."

In this study, we continue to bridge the gap between the development of sUASs and their application for hydrological climatology, focusing on demonstrating a range of moisture-related atmospheric phenomena that can be observed using this technique. As such, our main objective was to characterize land-atmosphere interactions at contrasting sites and across multiple weather conditions using an sUAS. In order to do so, the system was used to: (1) measure high-temporal-resolution profiles of temperature and dew point; (2) compare these variables across forested, mountainous, water, agricultural, and developed surfaces; and (3) detect rapid variations induced by changing weather conditions. We hypothesized that: (H1) temperature profiles will follow standard adiabatic lapse rates except in cases of steep topography, nearby water bodies, and impermeable surfaces; (H2) sources of water vapor flux to the atmosphere will be readily identifiable by steep, but persistent inflections in saturation ratio profile occurring near the ground or vegetative surface; and (H3) sUAS data collection will allow for visualization of rapidly changing boundary layer conditions, particularly over sources of heat and water vapor. 


\section{Materials and Methods}

2.1. Study Sites

Atmospheric profiles were collected at each of the following study sites. These locations were selected for their ability to demonstrate a range of environments and landatmosphere interaction phenomenon.

\subsubsection{Texas A\&M University Soltis Center for Research and Education, Costa Rica}

The Texas A\&M University (TAMU) Soltis Center for Research and Education is located near San Isidro, Costa Rica $\left(10^{\circ} 22^{\prime} 59.7^{\prime \prime} \mathrm{N}, 84^{\circ} 37^{\prime} 03.5^{\prime \prime} \mathrm{W}, 450\right.$ masl), in a premontane transitional rainforest situated between agricultural lands and the Monteverde cloud forest (Figure 1) [32,33]. This station is the only research site located in the transitional zone between lowland rainforest and lower montane cloud forest in Costa Rica, making it a novel place to conduct testing [34-36]. Nine flights were conducted from 2 July 2018, to 12 July 2018, at various times throughout the day (see Section 3.1 for specific times). The sUAS was launched each time from the Soltis Center parking lot which is at $452 \mathrm{~m}$ above sea level (masl). Vertical profiles were collected along the mountainside directly behind the Soltis Center and on the near and far ridges adjacent to the Soltis Center. An onsite meteorological tower and a canopy tower provided weather data during and throughout the summer of 2018 that measured relative humidity, precipitation, wind speed and direction, solar radiation, and barometric pressure at $2 \mathrm{~m}$ and $10 \mathrm{~m}$ above the ground surface.

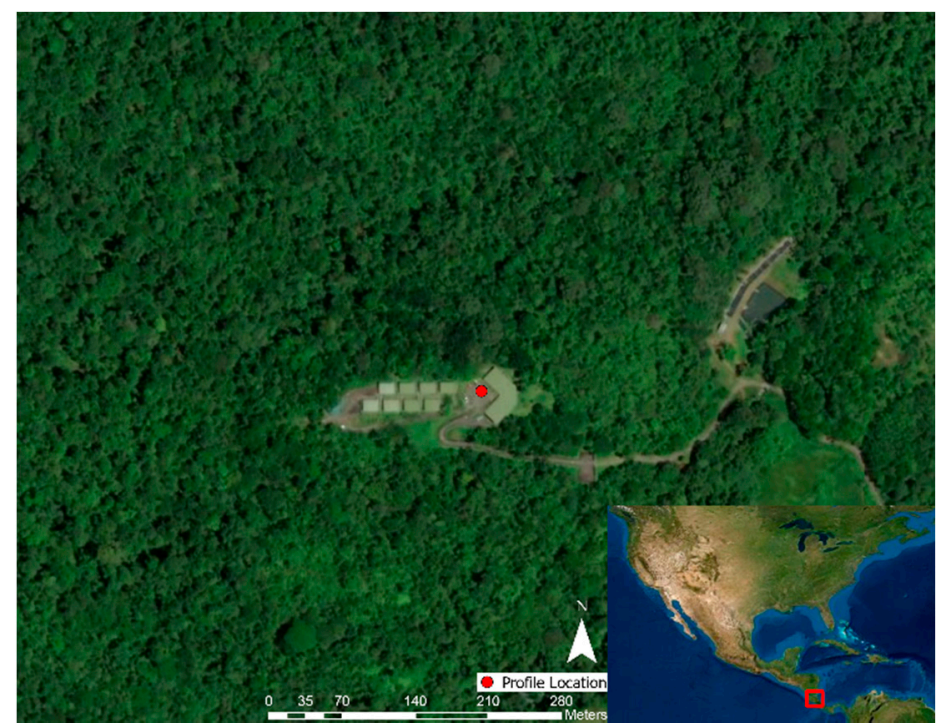

Figure 1. Soltis Center, San Isidro, Costa Rica site map with the parking lot profile launch location denoted (red dot). Above-forest profiles were taken in the included surrounding forest.

\subsubsection{Orange Lake, FL, USA}

Orange Lake is located in north central Florida, USA in Alachua county $\left(29^{\circ} 25^{\prime} \mathrm{N}\right.$, $\left.82^{\circ} 10^{\prime} \mathrm{W}, 20 \mathrm{masl}\right)$ and is one of the largest lakes in this region $\left(54 \mathrm{~km}^{2}\right)$. The lake is located in the south central and south east parts of the county. It is categorized by flatbottomed lakes and prairies with erosional remnants of the plateau in the north central part of Alachua county and has fluctuations in lake water level due to prevalent collapse sinkholes $[37,38]$. Three flights with a total of twelve profiles were collected in the late afternoon on 13 March 2019 (see Section 3.2 for specific times). All flights were launched from a ridge at elevation of 22 masl (Figure 2, location 1). Vertical profiles were collected over open pasture, over the lake, on the edge of an inland forest and on the edge of a forest bordering the lake (Figure 2, locations 2 to 4 , respectively). 


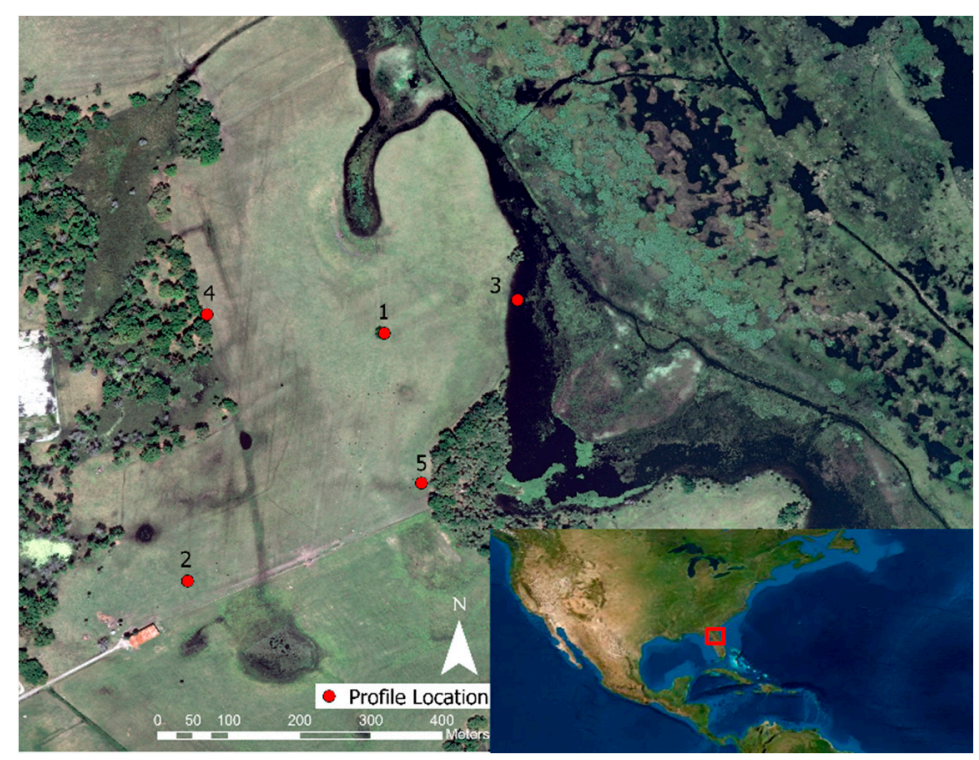

Figure 2. Orange Lake, FL, USA, site map with profile launch locations denoted (red dots). Profile 1 is located on a small ridge. Profile 2 is located over pasture. Profile 3 is located off shore over Orange Lake. Profile 4 is located on the edge of inland forest. Profile 5 is located on the outer edge of forest bordering Orange Lake.

\subsubsection{Morganton, GA, USA}

Morganton, Georgia $\left(34^{\circ} 49^{\prime} 45.1^{\prime \prime} \mathrm{N}, 84^{\circ} 10^{\prime} 30.2^{\prime \prime} \mathrm{W}, 690\right.$ masl) is located in the Blue Ridge Mountains, a subsection of the Appalachian Mountains, near the Chattahoochee National Forest characterized as primarily mixed oak (Quercus species) [39]. Four flights with four profiles each were collected on 28 December 2018, 1 January 2019, and 2 January 2019 (see Section 3.3 for specific times). The sUAS was launched at location 1 (Figure 2) which has an elevation of 696 masl. Vertical profiles were collected over development and in a natural forest clearing surrounded by deciduous forest in a valley (Figure 3, locations 1 and 2 , respectively).

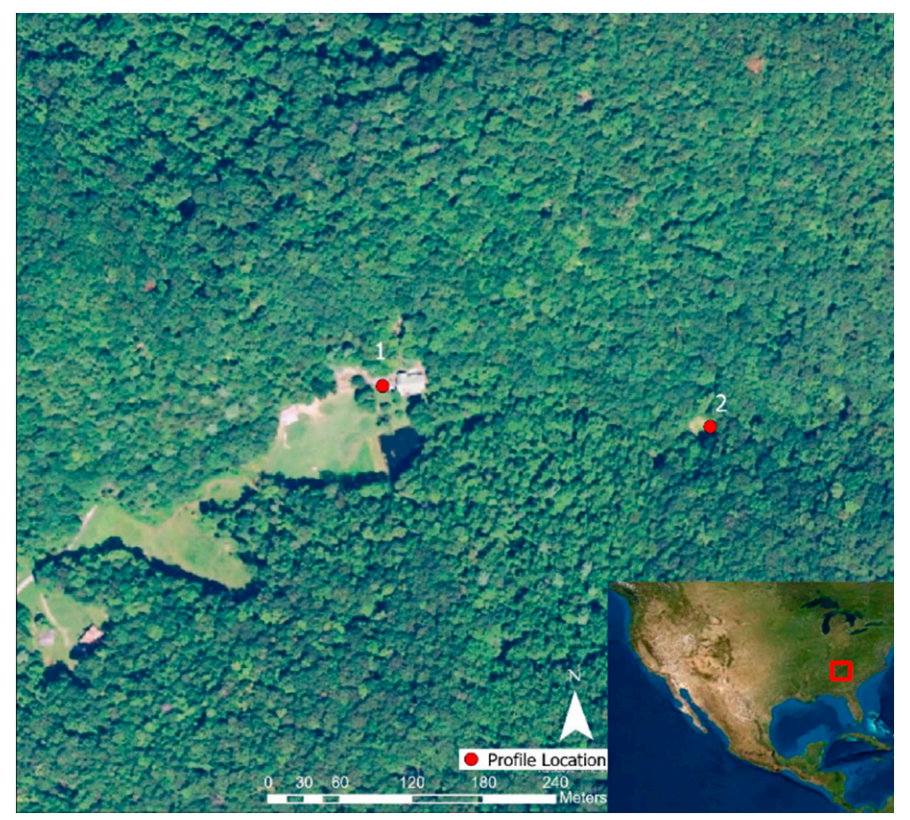

Figure 3. Morganton, GA, USA site map with profile launch locations denoted (red dots). Profile 1 is located over development. Profile 2 is located over a forest clearing. 


\section{2. sUAS Setup}

The sUAS consists of three components: a small multi-rotor unoccupied aerial vehicle (UAV), a Kestrel DROP D3FW Fire Weather Monitor (Kestrel Meters, Boothwyn, PA, USA), and a simple tether connecting these elements (Figure 4 and Table 1). The Kestrel DROP was used to collect relative humidity at a resolution of $1 \% \mathrm{RH}$ and temperature at a resolution of $0.1{ }^{\circ} \mathrm{C}$. Two different UAV models were used for the study: the Autel Robotics X-Star Premium (Autel Robotics, Bothell, WA, USA) in Costa Rica and the DJI Phantom 4 Pro V2.0 (DJI, Shenzhen, China) in Florida and Georgia. To record the meteorological data, the Kestrel DROP was tethered to the UAV landing gear using $7.6 \mathrm{~m}$ of plastic monofilament fishing line. This configuration allowed the sensor to experience undisturbed air and remain unaffected by the turbulence produced by the propellers [9]. Before each use, the sensor was allowed to equilibrate to its environment for at least $10 \mathrm{~min}$. After this initial equilibration, the sensor had a near-instantaneous response time to changes in $\mathrm{RH}$ and temperature. A 2-s averaging interval, the smallest available on the logger, was selected.

a)

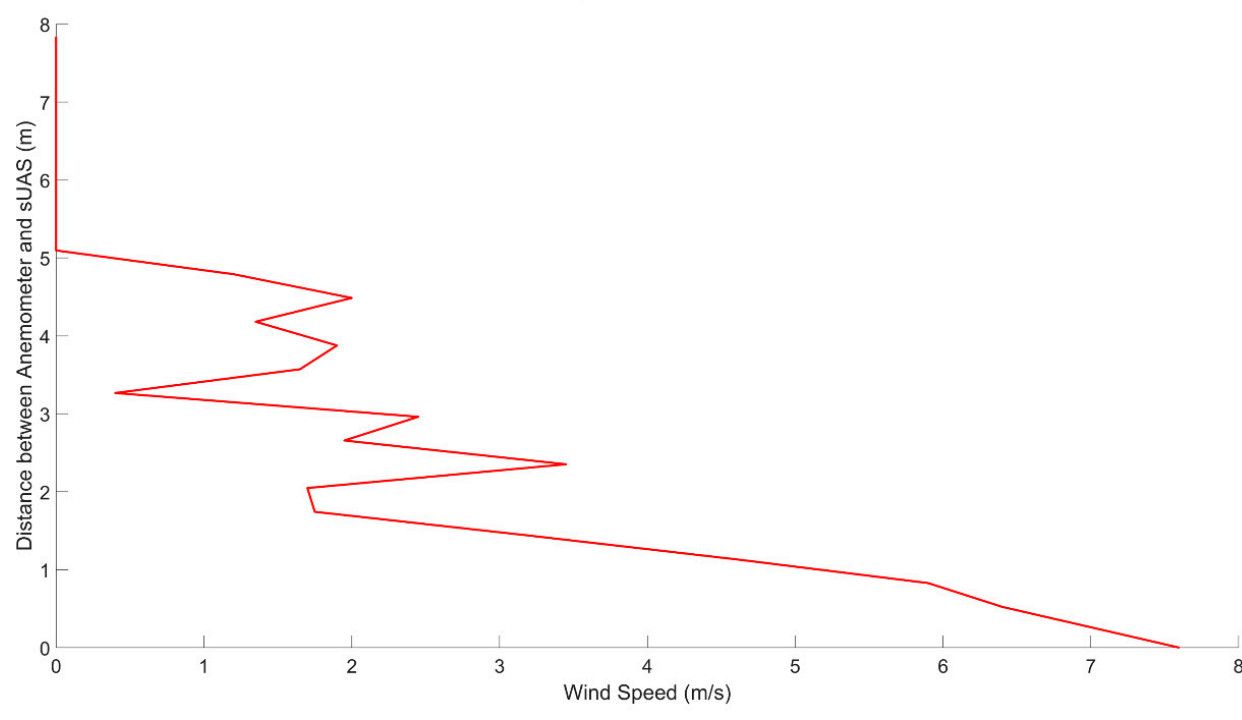

b)

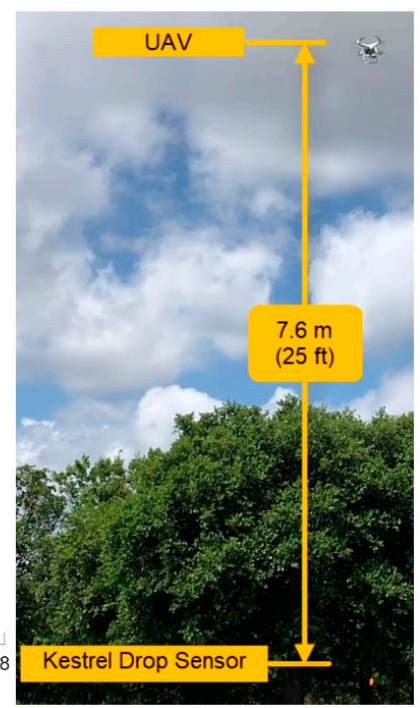

Figure 4. sUAS downdraft: (a) Vertical profile of wind speed measured at $0 \mathrm{~m}$ altitude as the sUAS rises, (b) resulting sUAS setup needed to eliminate the disturbance at the sensor location; a reprint from Prior et al. (2019) [40].

Table 1. sUAS platform specifications.

\begin{tabular}{cccc}
\hline & Aircraft 1 & Aircraft 2 & Sensor \\
\hline Company: & Autel Robotics, Bothell, WA, USA & DJI, Shenzhen, China & Kestrel Meters, Boothwyn, PA, USA \\
Model: & Autel Robotics X-Star Premium & DJI Phantom 4 Pro V2.0 & Kestrel DROP D3FW Fire Weather Monitor \\
Mass: & $1452 \mathrm{~g}$ & $1380 \mathrm{~g}$ & $34 \mathrm{~g}$ \\
Dimensions: & $352 \mathrm{~mm}$ diagonal & $350 \mathrm{~mm}$ diagonal & $24 \mathrm{~mm} \times 46 \mathrm{~mm} \times 60 \mathrm{~mm}$ \\
\hline
\end{tabular}

In order to determine how best to attach the sensors to the UAV, several tests were conducted to measure how far underneath the UAV the air was disturbed by the propellers. In order to do this, a wind gauge (Forestry Suppliers, Jackson, MS, USA) was held stationary one meter above ground level as the UAV hovered at varying altitudes. It was determined that the airspace was no longer disturbed by the propellers once the gap reached approximately $5.1 \mathrm{~m}$ (Figure 4). The sensors were tethered approximately $7.6 \mathrm{~m}$ from the landing gear of the UAV using monofilament to assure no effects from propeller downwash. They were then set to record measurements at their minimum interval (two seconds) in order to capture a complete vertical profile. Profiles recorded by UAV descents thus inserted the sensor into undisturbed air before downwash effects reached the sen- 
sor location. For cases where profiles were recorded during UAV ascents, the 2.5-m gap between the sensor and the disturbed air, the $1 \mathrm{~m} / \mathrm{s}$ vertical velocity, and the small size of the aircraft wake (approximately $60 \mathrm{~cm}$ wide) ensured negligible wake effects due to horizontal displacement of air for any ambient wind speed above $0.24 \mathrm{~m} / \mathrm{s}$, which was almost always the case.

\subsection{Field Measurements}

For all sUAS flights, a pilot controlled the flight path, line of sight was maintained, and altitude was limited to $122 \mathrm{~m}$ above ground level, as required by US Federal Aviation Administration (FAA) regulations governing research and educational applications [41]. Before each flight, the sensor was preset to record data every two seconds. While the sUAS was taking off from the launch site, the sensor and monofilament were held taut and slowly released as the sUAS rose to prevent the monofilament from being tangled in the propellers. The sUAS rose vertically upwards at $1 \mathrm{~m} / \mathrm{s}$ to the maximum altitude desired for each flight. It was then flown at that same altitude to one of the sample sites. Once over the sample site, the sUAS was then lowered at approximately $1 \mathrm{~m} / \mathrm{s}$ until the sensors were as close to the desired canopy as possible. A visual observer with binoculars acted as a spotter to assist this process and to ensure that the sensor did not become entangled in the canopy. The sUAS was then flown vertically upwards at $1 \mathrm{~m} / \mathrm{s}$ back to the maximum altitude. Other nearby sample sites were then visited, and vertical profiles were taken using the same procedure. The sUAS was then flown back over the launch site at the maximum altitude and then lowered. As the sUAS was lowered, the sensor was then caught by the visual observer and the monofilament was collected as the sUAS lowered to the ground. Once the sUAS landed, the sensor was collected, and the data from both the sensor and the sUAS were exported. In Costa Rica, the sensor was stored in desiccant between flights to avoid saturation in the humid environment. Flight patterns along with sUAS setup and selected data can be seen in the following data visualization from Prior et al. (2019) [40].

\subsection{Data Processing}

Data files from the atmospheric sensor and the sUAS were downloaded and combined to link altitude change with the recorded atmospheric variables and time. For each study site, the temperature in degrees Celsius $(T)$, dew point in degrees Celsius $\left(T_{d}\right)$, and atmospheric pressure in millibars $\left(p_{s t a}\right)$ were used to calculate vapor pressure in millibars $(e)$, water vapor mixing ratio $(w)$, saturation vapor pressure in millibars $\left(e_{s}\right)$, and saturation water vapor mixing ratio $\left(w_{s}\right)$ using Equations (1)-(4), respectively [42].

$$
\begin{gathered}
e=0.01 * 6.11 * \exp \left(\left(17.27 * T_{d}\right) /\left(237.3+T_{d}\right)\right) \\
w=621.97 * \exp \left(e /\left(p_{s t a}-e\right)\right) \\
e_{S}=6.11 * \exp ((17.27 * T) /(237.3+T)) \\
w_{s}=621.97 * \exp \left(e_{s} /\left(p_{\text {sta }}-e_{s}\right)\right)
\end{gathered}
$$

Data were binned such that all values collected within any given $2 \mathrm{~m}$ altitude interval were averaged and assigned to one height; this corresponded to the $1 \mathrm{~m} / \mathrm{s}$ ascent and the 2-s recording interval. Profiles of water mixing ratio and saturation water mixing ratio were used to compare the measured water vapor present in the atmosphere with the maximum potential water vapor that could exist at that particular temperature and pressure. Additionally, temperature profiles were compared to standard dry adiabatic lapse rate to determine if there were any effects from land surface features [42]. The closest standard dry lapse rate was chosen for each profile through graphical comparison. Corresponding altitude and position data were used from the onboard GPS within the sUAS, where timestamps were used to align the altitude data with the data collected from the tethered sensor. Dorn et al. (2016) found the accuracy for this type of GPS sensor to 
be within $2.80 \mathrm{~m}$ horizontally and $2.55 \mathrm{~m}$ vertically, negligible within the spatial scale of phenomena measured here.

\section{Results}

\subsection{Texas AEM University Soltis Center for Research and Education, Costa Rica}

The Soltis Center field campaign consisted of nine flights collected from 2 July 2018, to 9 July 2018, at various times throughout the day over the surrounding forest with flights lasting under $20 \mathrm{~min}$ (see Table 2 for specific times). The lowest part of the atmospheric profiles from the Soltis Center show the effect of the surface heat radiance from the asphalt parking surface, which sharply increased away from the lapse rate to $26^{\circ} \mathrm{C}$ (Figure 5a). Measurements starting at the same altitude as the forest profiles, around $25 \mathrm{~m}$, have the same general trend, with the parking lot profiles having slightly higher temperatures ranges $\left(24.1{ }^{\circ} \mathrm{C}\right.$ to $23.6^{\circ} \mathrm{C}$ versus $23.7^{\circ} \mathrm{C}$ to $\left.22.7^{\circ} \mathrm{C}\right)$ and water vapor mixing ratio ranges at saturation (20.1 ppt to $19.7 \mathrm{ppt}$ versus $19.6 \mathrm{ppt}$ to $18.7 \mathrm{ppt}$ ). Both the temperature profiles follow the dry adiabatic lapse rate with the parking lot having a slightly elevated ground level temperature $\left(24.2^{\circ} \mathrm{C}\right.$ versus $\left.24^{\circ} \mathrm{C}\right)$.

Table 2. Soltis Center flight start times, dates, and locations visited, with " $\mathrm{X}$ " denoting if the location was visited during the flight.

\begin{tabular}{cccc}
\hline Flight Number & Start Time & Parking Lot & Forest \\
\hline 1 & 2 July 2018 15:13 & $\mathrm{X}$ & \\
2 & 6 July 2018 13:43 & $\mathrm{X}$ & $\mathrm{X}$ \\
3 & 6 July 2018 16:03 & $\mathrm{X}$ & $\mathrm{X}$ \\
4 & 6 July 2018 18:02 & $\mathrm{X}$ & $\mathrm{X}$ \\
5 & 7 July 2018 11:58 & $\mathrm{X}$ & $\mathrm{X}$ \\
6 & 8 July 2018 10:52 & $\mathrm{X}$ & $\mathrm{X}$ \\
7 & 8 July 2018 12:48 & $\mathrm{X}$ \\
8 & 8 July 2018 16:36 & $\mathrm{X}$ & $\mathrm{X}$ \\
9 & 9 July 2018 6:57 & $\mathrm{X}$ & $\mathrm{X}$ \\
10 & 9 July 2018 10:29 & \\
\hline
\end{tabular}
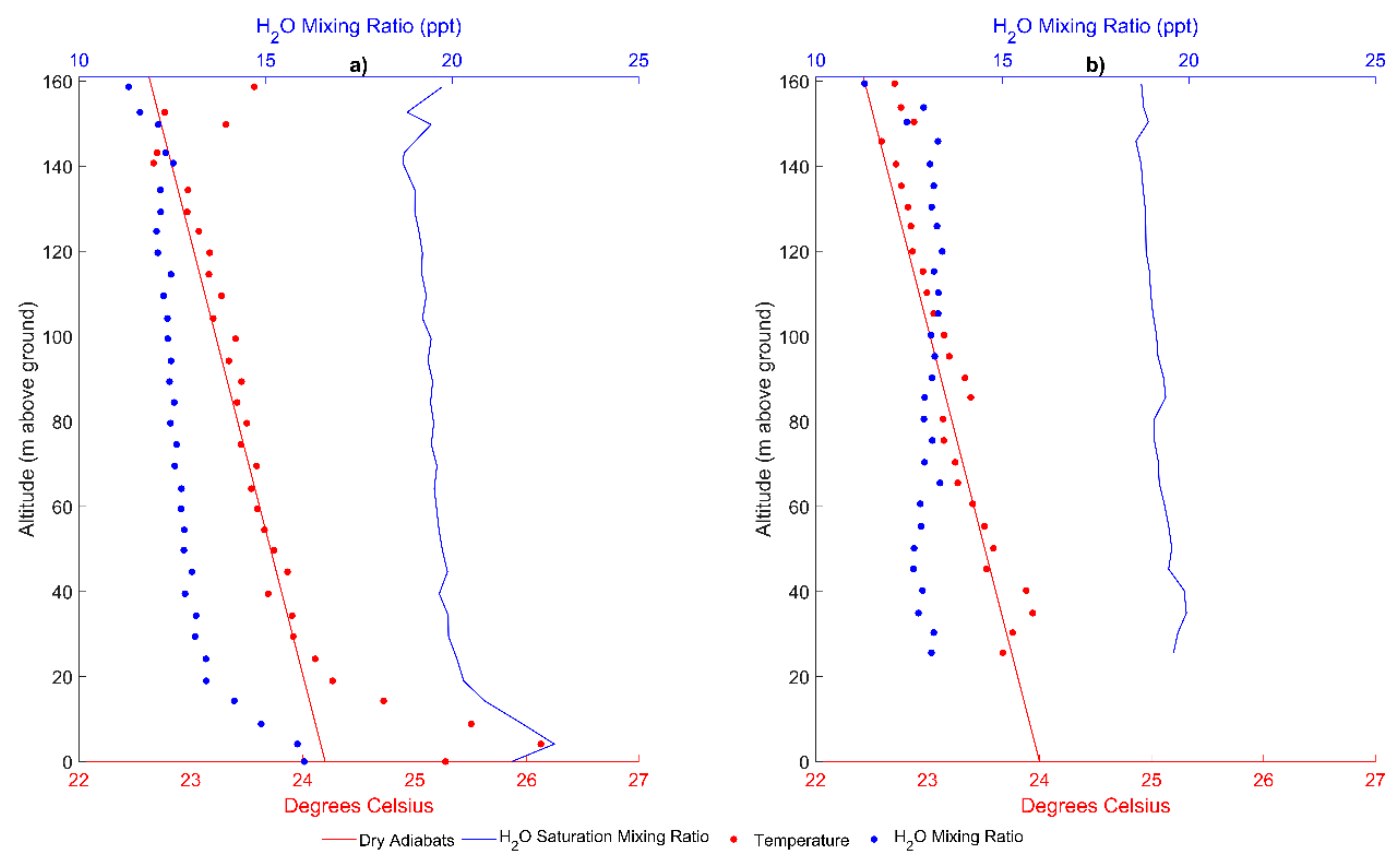

Figure 5. Average atmospheric profiles collected at the Soltis Center throughout from 2 July 2018 to 9 July 2018: (a) average air temperature (red dots), water vapor mixing ratio (blue dots), water vapor mixing ratio at saturation (blue line) and dry adiabatic lapse rate (red line) profiles over the parking lot, and (b) over the forest. 


\subsection{Orange Lake, $F L, U S A$}

The Orange Lake field campaign consisted of twelve profiles collected on 13 March 2019 (see Table 3 for specific times), over the locations described in Figure 2. The average air temperature profile (Figure 6) fits the dry adiabatic lapse consistently, with slight deviations at the lowest and highest altitudes. These low-altitude discrepancies can potentially be due to minute atmospheric changes occurring between ascents and descents, but are more likely attributable to the stark effect that landcover has on lapse rate deviations (Figure 7). Figure $7 \mathrm{c}$ has the most time elapsed $(2 \mathrm{~h}, 38 \mathrm{~min})$ between the first set of ascent and descent profiles (16:42) shown in the two darkest sets of points to the second set of ascent and descent profiles (18:04) shown in the two lightest sets of points. The other subplots (Figure $7 \mathrm{~b}$ to Figure $7 \mathrm{e}$ ) have one set of ascent and descent profiles that were collected within minutes of each other.

Table 3. Orange Lake flight start times, dates, and locations visited, with " $\mathrm{X}$ " denoting if the location was visited during the flight.

\begin{tabular}{ccccccc}
\hline $\begin{array}{c}\text { Flight } \\
\text { Number }\end{array}$ & Start Time & $\begin{array}{c}\mathbf{1} \\
\text { Ridge }\end{array}$ & $\begin{array}{c}\mathbf{2} \\
\text { Pasture }\end{array}$ & $\begin{array}{c}3 \\
\text { Lake }\end{array}$ & $\begin{array}{c}\text { Next to Forest Furthest } \\
\text { from the Lake }\end{array}$ & $\begin{array}{c}\text { Next to Forest near } \\
\text { the Lake }\end{array}$ \\
\hline 1 & 13 Mar 2018 16:42 & $X$ & & $X$ & $X$ & $X$ \\
3 & 13 Mar 2018 17:11 & & $X$ & $X$ & \\
\hline
\end{tabular}

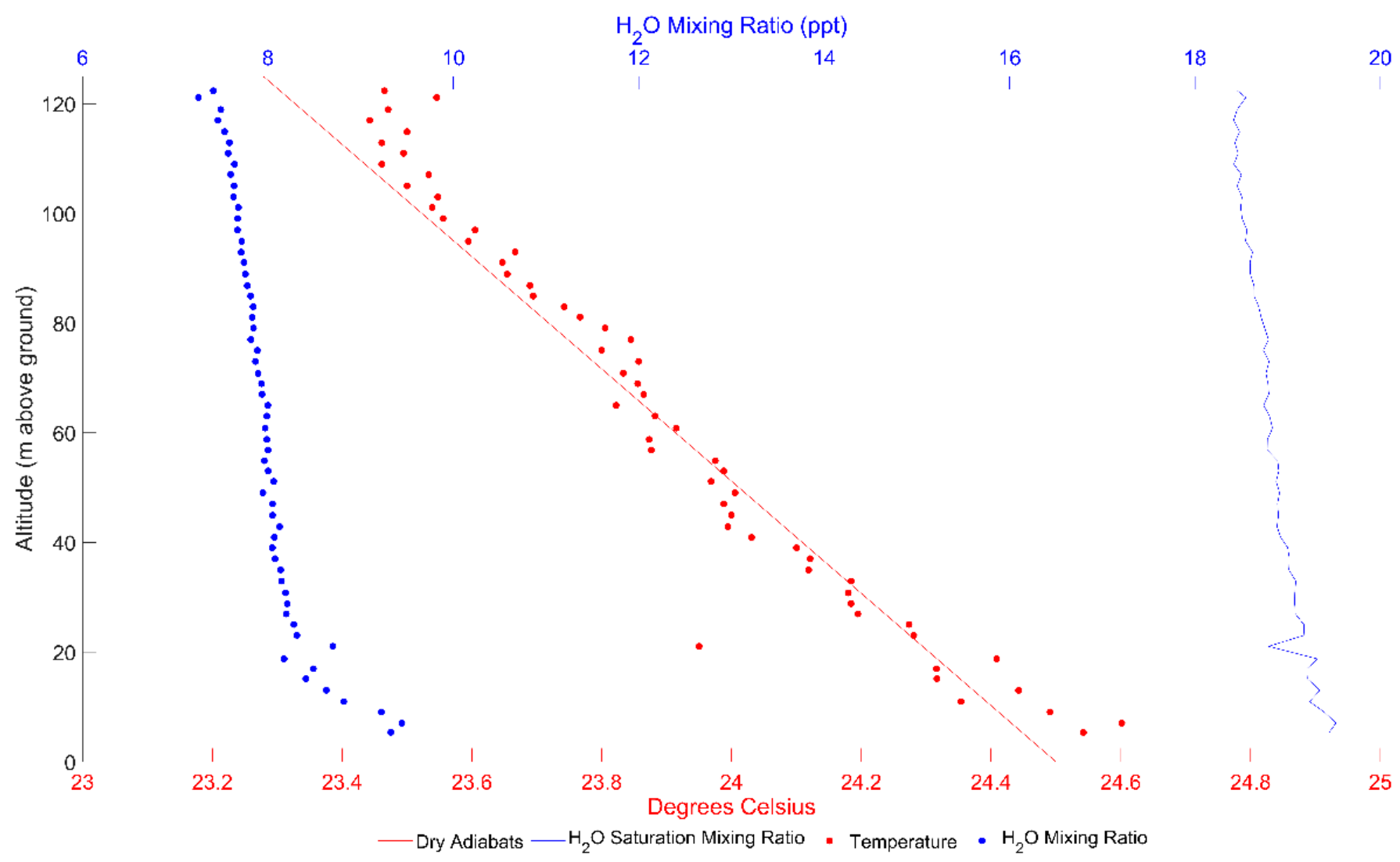

Figure 6. Average air temperature (red dots), water vapor mixing ratio (blue dots), water vapor mixing ratio at saturation (blue line), and dry adiabatic lapse rate (red line) profiles collected at Orange Lake, FL, USA on 13 March 2019. 

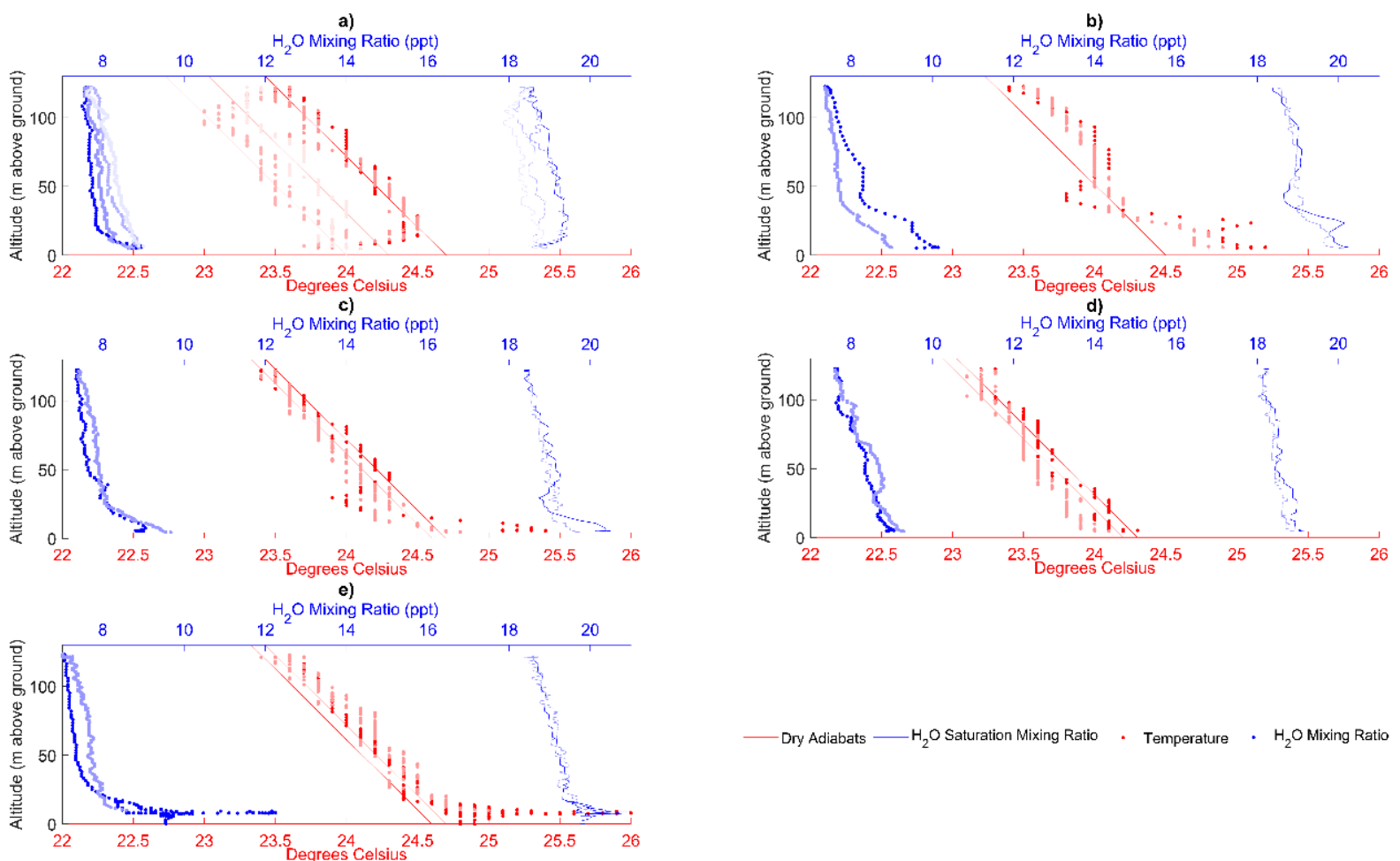

- Dry Adiabats —- $\mathrm{H}_{2} \mathrm{O}$ Saturation Mixing Ratio . Temperature - $\mathrm{H}_{2} \mathrm{O}$ Mixing Ratio

Figure 7. Atmospheric profiles collected at Orange Lake, FL, USA on 13 March 2019. Shading indicates ascent/descent order, with lighter values showing later times: (a) average air temperature (red dots), water vapor mixing ratio (blue dots), water vapor mixing ratio at saturation (blue line), and dry adiabatic lapse rate (red line) profiles at location 3 over the lake; (b) profiles at location 5 next to the forest near the lake; (c) at location 4 next to the forest furthest from the lake; (d) at location 2 over pasture; and (e) at location 1 over the ridge.

\subsection{Morganton, GA, USA}

The Morganton field campaign consisted of eight profiles (two per flight) collected from 28 December 2018, to 2 January 2019 (see Table 4 for specific times), over the locations described in Figure 3. The temperature over the parking lot is influenced by the asphalt's low albedo and subsequently high emission of heat. This alters the average temperature profile near the lower elevations, and makes it slightly hotter overall than the forest clearing profile (Figure 8) $\left(14.2\right.$ to $11.7^{\circ} \mathrm{C}$ versus 12.3 to $\left.11.6^{\circ} \mathrm{C}\right)$. The average air temperature profile (Figure $8 \mathrm{~b}$ ) was not consistent with the dry adiabatic lapse rate, even without the inversion profiles seen in Figure 9, with differences at the lowest altitude being approximately $0.8^{\circ} \mathrm{C}$ and at the highest altitude being $0.5^{\circ} \mathrm{C}$. Terrain influence of the surrounding mountains is potentially responsible for these deviations. The midmorning flight on 2 January 2019, recorded a dramatic inversion (Figure 9). Figure 9a exhibits the influence of the land surface at the lowest altitude, followed by a tight alignment with a dry adiabatic lapse rate (12.3 to $14{ }^{\circ} \mathrm{C}$ in $9 \mathrm{~m}$ of altitude). The profile then increases at $42 \mathrm{~m}$ and starts following an increased adiabatic lapse rate at $145.2 \mathrm{~m}\left(9.2^{\circ} \mathrm{C}\right.$ lapse rate versus $14.4^{\circ} \mathrm{C}$ lapse rate). The forest clearing profile follows a similar trend, but does not follow a clear lapse rate and has the temperature increase starting at $62.5 \mathrm{~m}$.

Table 4. Morganton flight start times, dates, and locations visited, with " $\mathrm{X}$ " denoting if the location was visited during the flight.

\begin{tabular}{cccc}
\hline Flight Number & Start Time & Parking Lot & Forest Clearing \\
\hline 1 & 28 Dec 2018 18:16 & $\mathrm{X}$ & $\mathrm{X}$ \\
2 & 1 Jan 2019 12:00 & $\mathrm{X}$ & $\mathrm{X}$ \\
3 & 1 Jan 2019 16:03 & $\mathrm{X}$ & $\mathrm{X}$ \\
4 & 2 Jan 2019 9:49 & $\mathrm{X}$ & $\mathrm{X}$ \\
\hline
\end{tabular}




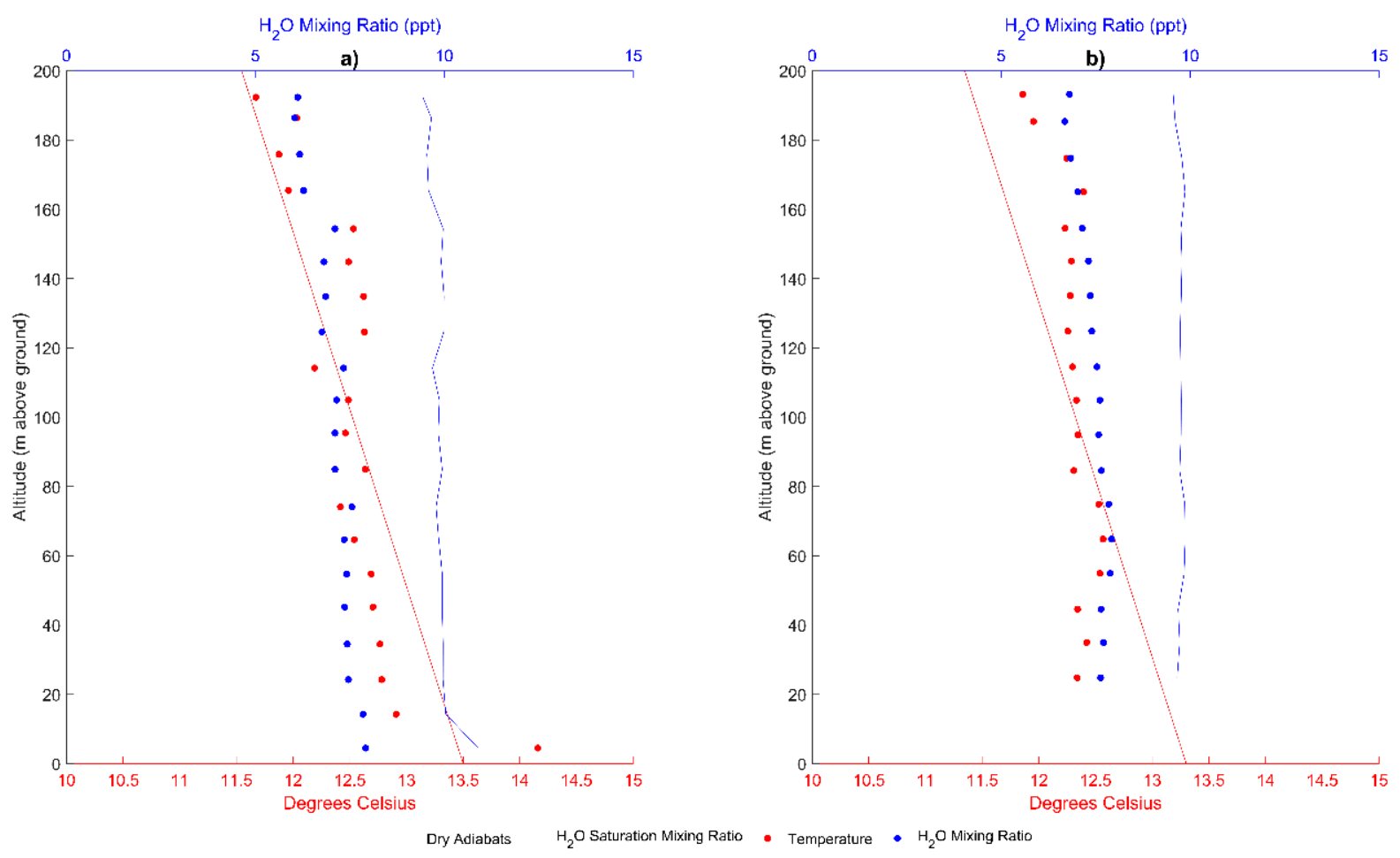

Figure 8. Average atmospheric profiles collected at Morganton, GA, USA without the inversion profiles seen in Figure 9: (a) average air temperature (red dots), water vapor mixing ratio (blue dots), water vapor mixing ratio saturation (blue line), and dry adiabatic lapse rate (red line) profiles over the parking lot, and (b) over the forest clearing.

a)

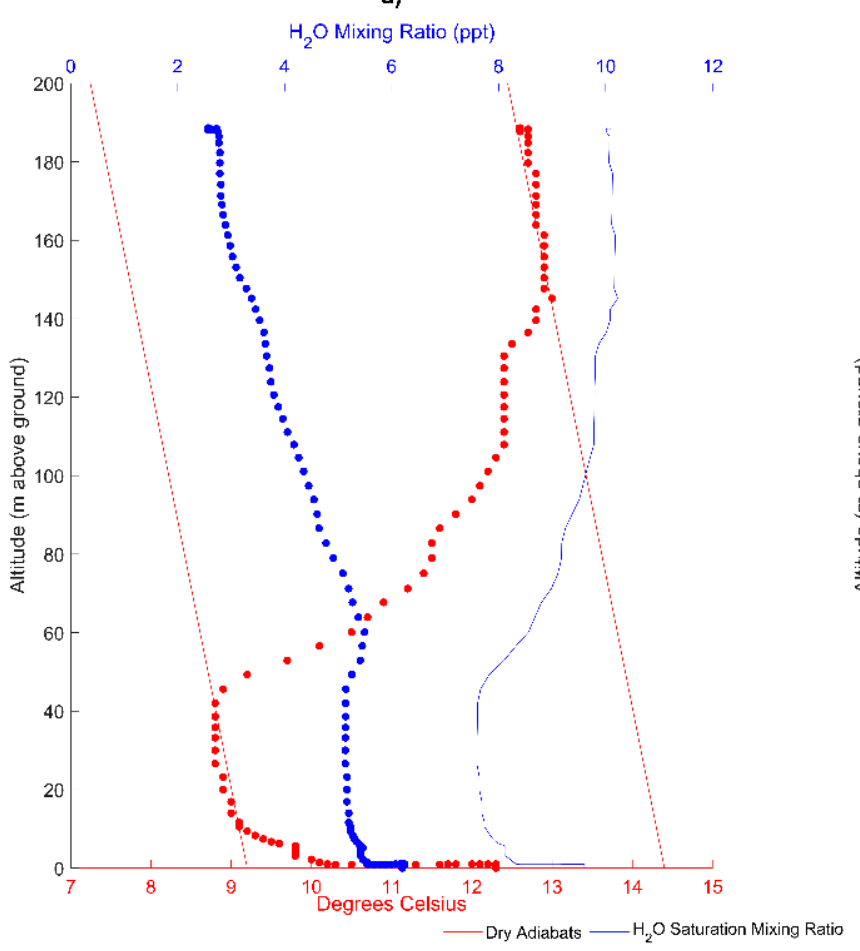

b)

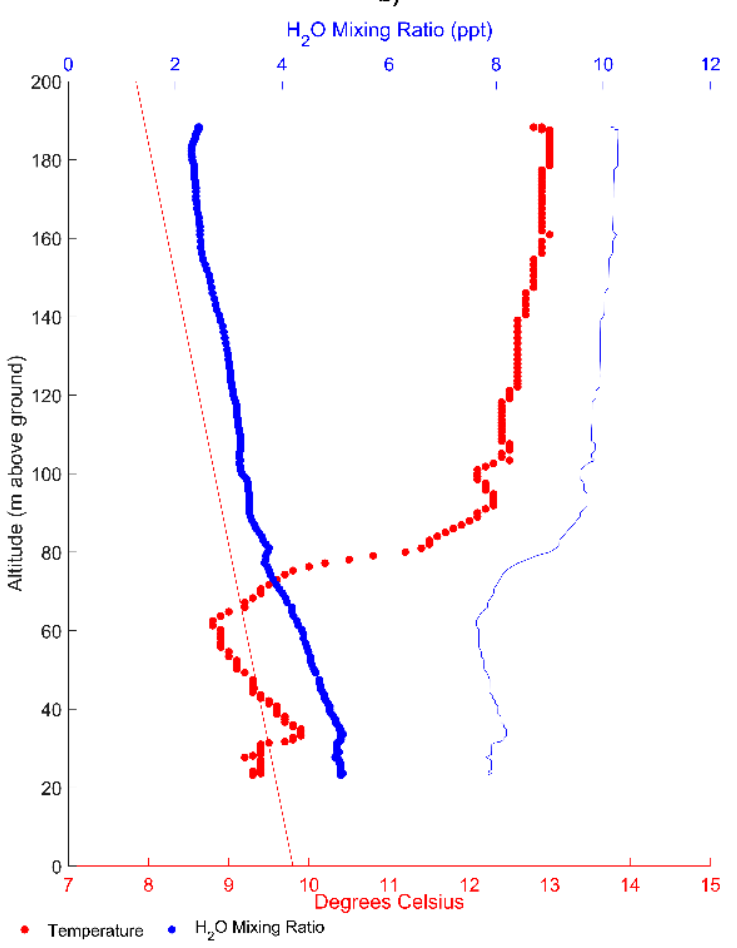

Figure 9. Morganton, Georgia inversion occurring at 9:50 on 2 January 2019: (a) air temperature (red dots), water vapor mixing ratio (blue dots), water vapor mixing ratio at saturation (blue line), and adiabatic lapse rate (red line) profiles over the parking lot, and (b) over the forest clearing. 


\section{Discussion}

From the Soltis Center average profiles, the asphalt parking surface has a lasting effect on both air temperature and mixing ratio when compared to the forest average profile (Figures 5 and 10). The obvious difference between the two profiles is the effect of radiative heat from the unobstructed surface of the asphalt parking surface. Despite this initial influence, once the parking lot profiles reach the same height as the canopy profiles, around $35 \mathrm{~m}$, the parking lot temperature profile is still slightly hotter than the forest temperature profile (Figure 10). The asphalt parking surface also has a lasting effect on water vapor concentrations. There is a decrease in mixing ratio over the asphalt parking surface as altitude increases, while there is a concave increase in mixing ratio over the forest. These near-surface atmospheric trends can be attributed to the landcover and terrain. The asphalt parking surface, and potentially land development in general, absorbs and emits more heat than the surrounding forest, thus creating a heat island effect. The forest generally has cooler temperatures due to shading and evapotranspiration. Combining these, along with the frequent rains, mixing ratio increases over the rainforest. Additionally, this rainforest can be classified as transitional, since it lies between high-elevation cloud forests and lowland agriculture. The flights were also conducted on the downgradient of a nearby mountain (peak at approximately $730 \mathrm{~m}$ elevation gain from launch site). This elevational gradient could have also instigated some rain shadow effect, thus further affecting the mixing ratio standard deviation cloud in Figure 10.

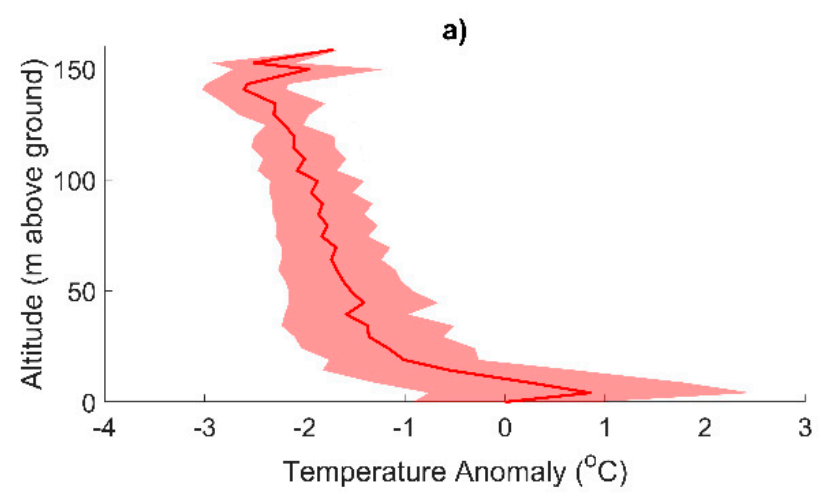

c)

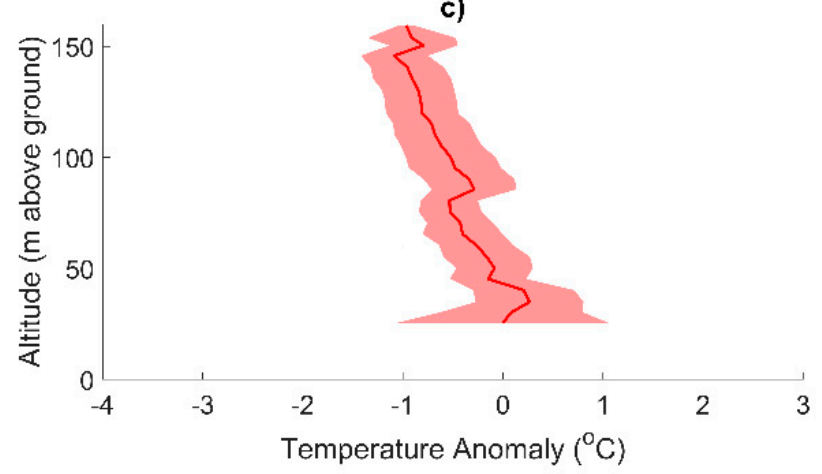

b)

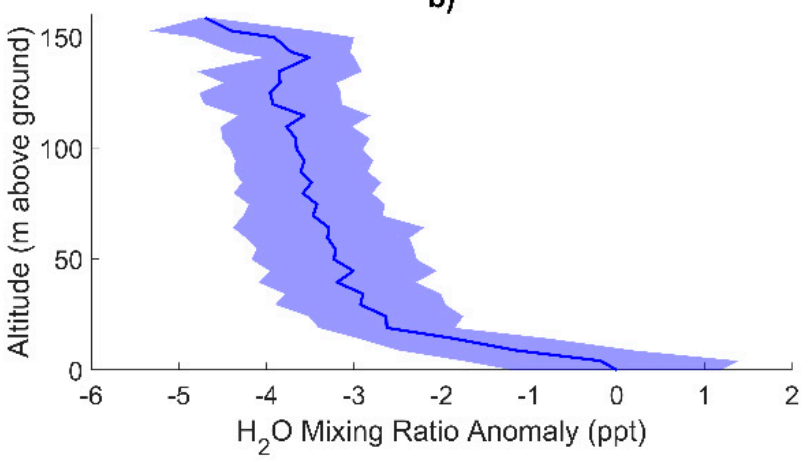

d)

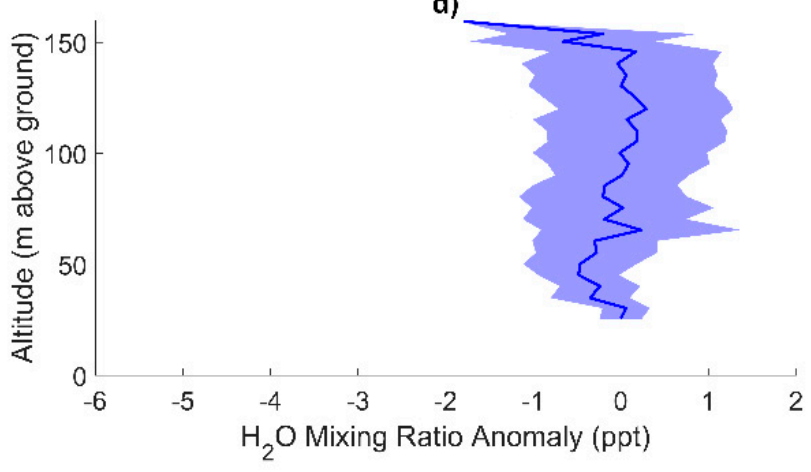

Figure 10. Normalized average Soltis Center profiles with the dark center line as the normalized average and the shaded area as one standard deviation. Normalization was achieved by using the reading at the lowest elevation of each profile: (a) parking lot normalized temperature average with one standard deviation cloud, (b) parking lot normalized water vapor mixing ratio average with one standard deviation cloud, (c) forest normalized temperature average with one standard deviation cloud, and (d) forest normalized water vapor mixing ratio average with one standard deviation cloud.

For the Florida study site, the open pasture, over which most of the profiles were collected, exhibited a similar but dampened low albedo radiation effect to the asphalt parking surface in Costa Rica (Figures 6 and 11). This same heat effect can further be seen in greater detail in Figure $7 \mathrm{~b}-\mathrm{e}$. The absence of the low albedo surface can clearly be seen 
in Figure 7a, where the profiles were collected just off shore over the lake. The profiles in Figure 7a show the exact opposite trend for both the temperature and saturation mixing ratio profiles by starting low at the surface, due to the lake cooling the air directly above, with a rapid increase to a somewhat steady negative trend with increased altitude. This observed trend is dampened with diurnal temperature changes (darkest profiles were collected at 4:42 p.m. while lightest profiles were collected at 5:40 p.m.). Similar to the large moisture source of the rainforest, the $54 \mathrm{~km}^{2}$ lake influenced the Florida study site. Despite the quick data collection turnaround of mere minutes, ascent and descent profiles still exhibit distinctive differences (Figure $7 \mathrm{~b}-\mathrm{e}$ ). The variation between the ascent and descent profiles were probably caused by water vapor emitting from the lake coupled with gusts of winds up to $11.2 \mathrm{~m} / \mathrm{s}(25 \mathrm{mph})$. Forest shadowing clearly influenced these ratios, as the profiles do not show a clear trend till above the tree canopy altitude (Figure $7 \mathrm{~b}, \mathrm{c}$ ).
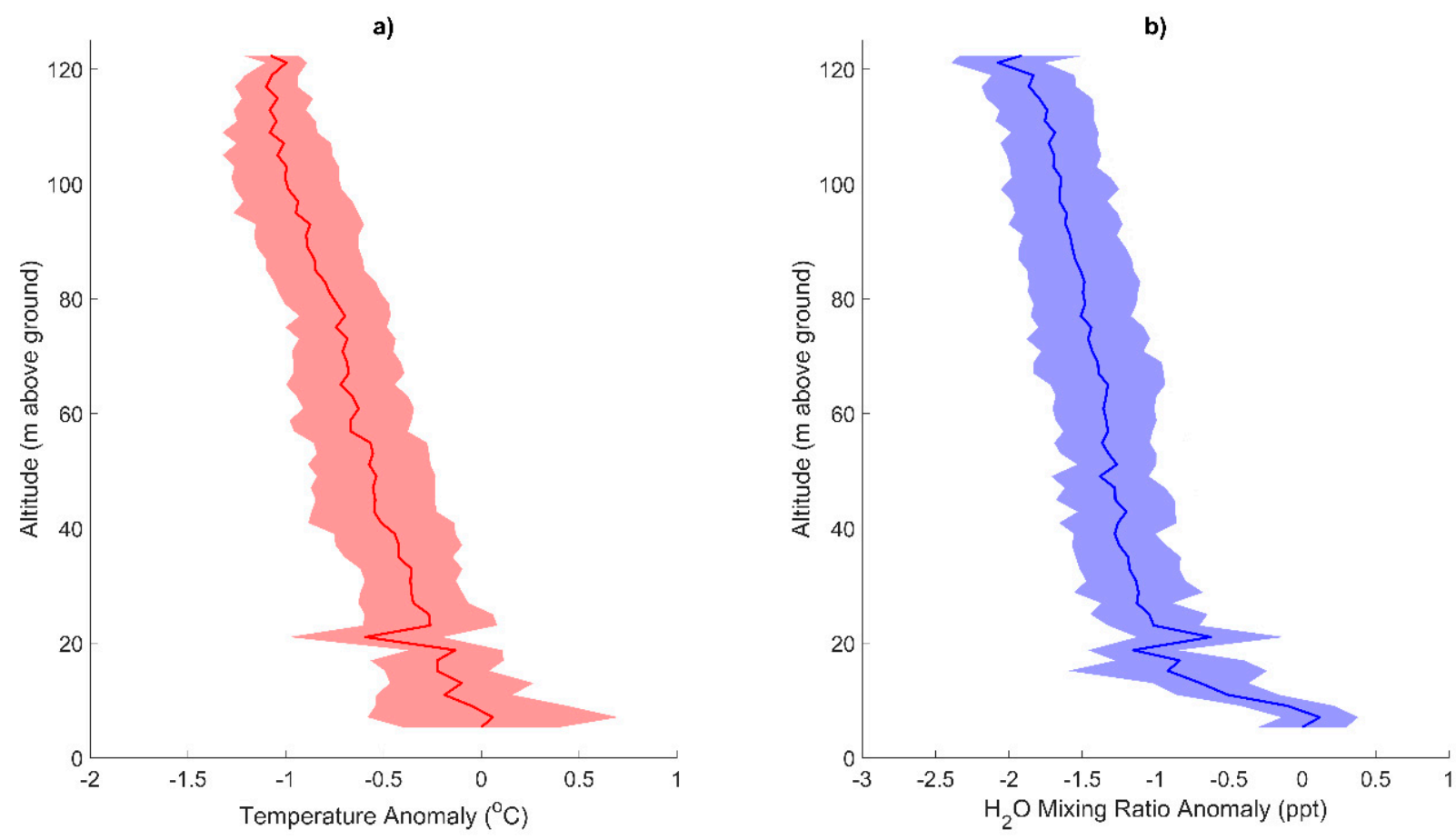

Figure 11. Normalized average Orange Lake profiles with the dark center line as the normalized average and the shaded area as one standard deviation. Normalization was achieved by using the reading at the lowest elevation of each profile: (a) normalized temperature average with one standard deviation cloud, and (b) normalized water vapor mixing ratio average with one standard deviation cloud.

At the Georgia site, terrain had the most distinctive effect on the profiles. Profiles were taken in a valley between two ridge lines of approximately $122 \mathrm{~m}$ of elevation gain to the north and approximately $133 \mathrm{~m}$ of elevation gain to the south. Above these altitudes, deviations from the average profile decrease and the inversion is no longer influential (Figures 9 and 12). Similar to the other sights, the paved surface had high radiant heat effects to the temperature profiles with high temperatures at low altitudes, as well as shifting the entire average temperature profile to higher temperatures than the average profile over the forest clearing (Figures 8, 9, and 12). Additionally, colder moist air seems to occur somewhat near the surface (Figure $9 \mathrm{a}$ from 10 to $42 \mathrm{~m}$, Figure $9 \mathrm{~b}$ from 23 to $70 \mathrm{~m}$ ) due to cooling from landcover moisture and trapped air below the higher altitude inversion. Landcover cooling effect is no longer influential above $43 \mathrm{~m}$ for the paved surface and 71 $\mathrm{m}$ for the forest clearing (Figure 9) as temperatures increase and moisture decreases with altitude. 


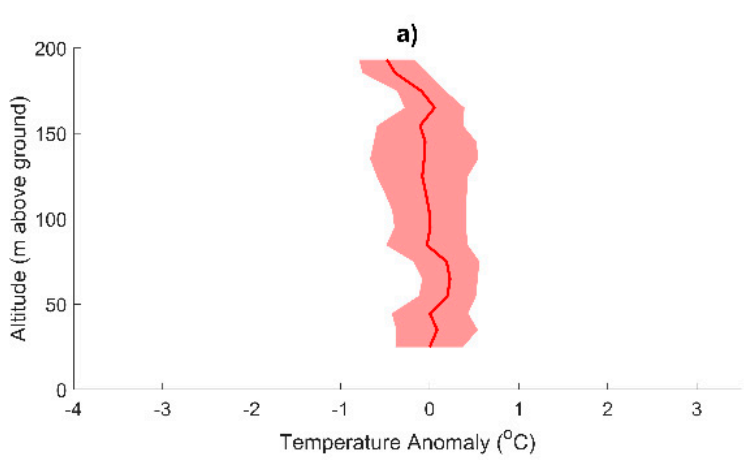

c)

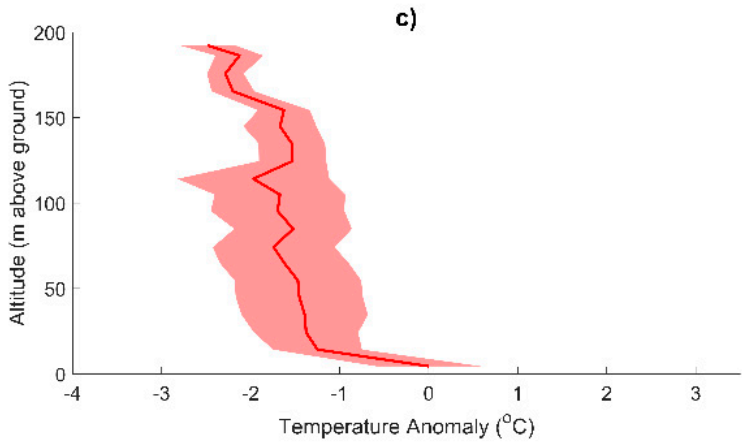

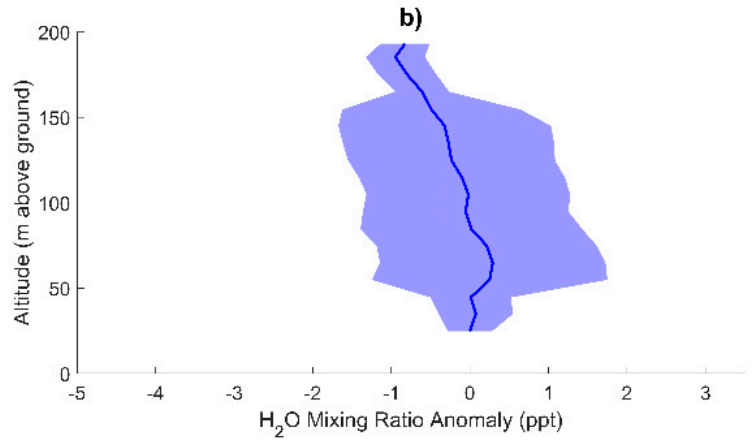

d)

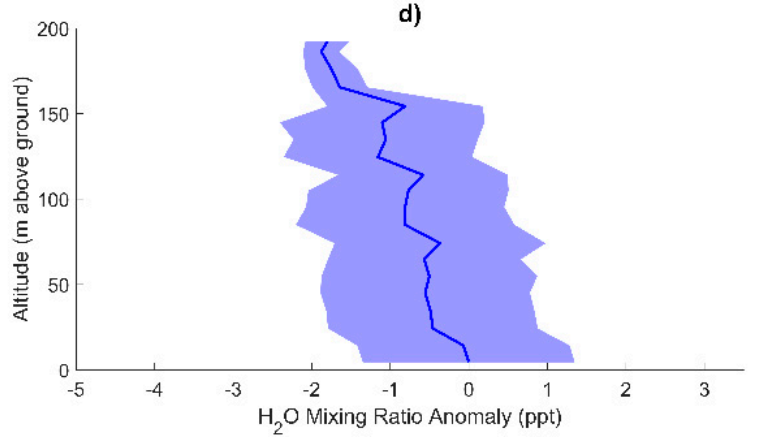

Figure 12. Normalized average Georgia profiles with the dark center line as the normalized average and the shaded area as one standard deviation. Normalization was achieved by using the reading at the lowest elevation of each profile: (a) normalized temperature average with one standard deviation cloud over the parking lot, (b) normalized water vapor mixing ratio average with one standard deviation cloud over parking lot, (c) normalized temperature average with one standard deviation cloud over forest clearing, and (d) normalized water vapor mixing ratio average with one standard deviation cloud over forest clearing.

From the profiles collected over various land surfaces, several common trends were observed. Atmospheric anomalies occur consistently for all study sites between the ground surface and approximately $20 \mathrm{~m}$ in altitude which can be attributed to landcover (Figures 10-12). Above approximately $20 \mathrm{~m}$, profiles followed expected standard adiabatic lapse rates, except for the Georgia site, for which, due to the valley temperature inversion, a standard adiabatic lapse rate was followed starting at about $140 \mathrm{~m}$. Topographic influences, such as mountains, seem to cause a wide spread in profile data (Figure 12). Nearby lakes and forests influence surrounding near-surface atmosphere by either inducing or reducing water vapor flux (Figure 7). The sUAS's ability to collect profiles within minutes of the last profile allowed for the observation of rapid sub-diurnal changes of the near-surface boundary layer condition, such as observing water vapor flux from a nearby lake (Figure 7c), water mixing ratio extremes over a lake (Figure 7a), and temperature inversion variation in mountainous terrain (Figure 9). From these observations, temperature profiles closely followed the expected standard adiabatic lapse rate above $20 \mathrm{~m}$; below $20 \mathrm{~m}$, the landcover, topography, and nearby water vapor sources greatly influenced profiles. Additionally, sources of water vapor flux, such as water bodies and vegetation, influenced the nearsurface profiles by increasing water mixing ratio (approximately below $20 \mathrm{~m}$ ). At each site, the platform successfully enabled data visualization of boundary layer variability from heat and water vapor sources over short periods of time and throughout the day. Overall, the sUAS platform was able to observe and characterize land-atmospheric interactions across multiple sites that offered various landcover types, weather conditions, and topographic features while also observing rapid profile variations.

One improvement for this study includes collecting traditional atmospheric data for comparison to the sUAS data, either through collection at the launch site or conducting flights next to a meteorological profile tower [43,44]. Additionally, consistent temporal collection of profiles, every $2 \mathrm{~h}$ for $24 \mathrm{~h}$, would allow for proper sub-diurnal analysis. This 
would, however, present the additional challenge of piloting at night, and for the Costa Rica site, during heavy morning and evening fog events.

\section{Conclusions}

In order to investigate the sUAS's ability to detect land-atmospheric interactions, this study collected atmospheric profile data over three distinct landscapes that offered various landcover types, weather conditions, and topographic features. The sUAS platform was able to collect high-temporal- and geospatial-resolution profiles of temperature and dew point over water, forested, mountainous, agricultural, and developed surfaces while observing rapid temperature and vapor flux variability. From this study, the sUAS observed normal adiabatic lapse rates except in the presence of dramatic topography, adjacent water bodies, and impermeable human-made surfaces. Sources of water vapor fluctuations were observed from both vegetation and water bodies through the mixing ratio profiles. This system was also able to collect data on the minute variability of the near-surface boundary layer, especially over heat and water sources. This study offers insight into surface atmospheric influences that could be difficult to observe using stationary sensors or in modeled scenarios.

Future work should include regimented sub-diurnal flights with baseline atmospheric data collection for sUAS comparison, while also including other atmospheric sensors. Natural expansion from the research conducted in this study includes collection of profiles over various landcover types with no topographic features and then landcover types with topographic features to better isolate topography influences on near-surface atmospheric processes. Additionally, a carbon dioxide sensor could be included in the sUAS sensor package, which would enhance understanding of biological processes and carbon cycling.

Author Contributions: Conceptualization and literature review were carried out by G.R.M.; Funding acquisition was achieved by G.R.M. and K.B.; Data collection was performed by K.B. and E.M.P.; Experimental design, data analysis, results interpretation, and manuscript preparation were performed by E.M.P., G.R.M. and K.B. All authors have read and agreed to the published version of the manuscript.

Funding: This work has been supported by the National Science Foundation through a Research Experiences for Undergraduates (REU) site grant (EAR-1659848), National Robotics Initiative grant (IIS-1925148), and the Interdisciplinary Graduate Education Program in Remote Sensing at Virginia Tech.

Institutional Review Board Statement: Not applicable.

Informed Consent Statement: Not applicable.

Acknowledgments: The authors would like to thank the staff at the Soltis Center for Education and Research in San Isidro de Peñas Blancas, Costa Rica, for providing access to the rainforest sites, as well as Georgianne Moore for her leadership of the Texas A \& M Costa Rica REU.

Conflicts of Interest: The authors declare no conflict of interest.

\section{References}

1. National Academies of Sciences, Engineering and Medicine. Thriving on Our Changing Planet: A Decadal Strategy for Earth Observation from Space; The National Academies Press: Washington, DC, USA, 2018; ISBN 978-0-309-46757-5.

2. Council, N.R. Observing Weather and Climate from the Ground Up: A Nationwide Network of Networks; The National Academies Press: Washington, DC, USA, 2009; ISBN 978-0-309-12986-2.

3. Elston, J.; Argrow, B.; Stachura, M.; Weibel, D.; Lawrence, D.; Pope, D. Overview of Small Fixed-Wing Unmanned Aircraft for Meteorological Sampling. J. Atmos. Ocean. Technol. 2015, 32, 97-115. [CrossRef]

4. Martin, S.; Bange, J.; Beyrich, F. Meteorological Profiling of the Lower Troposphere Using the Research UAV “M2AV Carolo". Atmos. Meas. Tech. 2011, 4, 705. [CrossRef]

5. Reuder, J.; Jonassen, M.O.; Ólafsson, H. The Small Unmanned Meteorological Observer SUMO: Recent Developments and Applications of a Micro-UAS for Atmospheric Boundary Layer Research. Acta Geophys. 2012, 60, 1454-1473. [CrossRef]

6. Mayer, S.; Sandvik, A.; Jonassen, M.O.; Reuder, J. Atmospheric Profiling with the UAS SUMO: A New Perspective for the Evaluation of Fine-Scale Atmospheric Models. Meteorol. Atmos. Phys. 2012, 116, 15-26. [CrossRef] 
7. Rautenberg, A.; Schön, M.; Zum Berge, K.; Mauz, M.; Manz, P.; Platis, A.; van Kesteren, B.; Suomi, I.; Kral, S.T.; Bange, J. The Multi-Purpose Airborne Sensor Carrier MASC-3 for Wind and Turbulence Measurements in the Atmospheric Boundary Layer. Sensors 2019, 19, 2292. [CrossRef] [PubMed]

8. Hemingway, B.L.; Frazier, A.E.; Elbing, B.R.; Jacob, J.D. Vertical Sampling Scales for Atmospheric Boundary Layer Measurements from Small Unmanned Aircraft Systems (SUAS). Atmosphere 2017, 8, 176. [CrossRef]

9. Machado, C.R. An Analysis of Meteorological Measurements Using a Miniature Quad-Rotor Unmanned Aerial System. Master's Thesis, Naval Postgraduate School, Monterey, CA, USA, 2015.

10. Walther, J.; PytlikZillig, L.; Detweiler, C.; Houston, A. How People Make Sense of Drones Used for Atmospheric Science (and Other Purposes): Hopes, Concerns, and Recommendations. J. Unmanned Veh. Syst. 2019, 7, 219-234. [CrossRef]

11. Barbieri, L.; Kral, S.T.; Bailey, S.C.; Frazier, A.E.; Jacob, J.D.; Reuder, J.; Brus, D.; Chilson, P.B.; Crick, C.; Detweiler, C. Intercomparison of Small Unmanned Aircraft System (SUAS) Measurements for Atmospheric Science during the LAPSE-RATE Campaign. Sensors 2019, 19, 2179. [CrossRef]

12. Segales, A.R.; Greene, B.R.; Bell, T.M.; Doyle, W.; Martin, J.J.; Pillar-Little, E.A.; Chilson, P.B. The CopterSonde: An Insight into the Development of a Smart Unmanned Aircraft System for Atmospheric Boundary Layer Research. Atmos. Meas. Tech. 2020, 13, 2833-2848. [CrossRef]

13. Islam, A.; Houston, A.L.; Shankar, A.; Detweiler, C. Design and Evaluation of Sensor Housing for Boundary Layer Profiling Using Multirotors. Sensors 2019, 19, 2481. [CrossRef]

14. Foster, N.P.; Pinkerman, C.W.; Jacob, J.D. Meteorological Data Collection for Three-Dimensional Forecasting Advancements; American Institute of Aeronautics and Astronautics: Reston, VA, USA, 13 June 2016; p. 4195.

15. Brewer, M.J.; Clements, C.B. Meteorological Profiling in the Fire Environment Using UAS. Fire 2020, 3, 36. [CrossRef]

16. Koch, S.E.; Fengler, M.; Chilson, P.B.; Elmore, K.L.; Argrow, B.; Andra, D.L., Jr.; Lindley, T. On the Use of Unmanned Aircraft for Sampling Mesoscale Phenomena in the Preconvective Boundary Layer. J. Atmos. Ocean. Technol. 2018, 35, 2265-2288. [CrossRef]

17. Nolan, P.J.; Pinto, J.; González-Rocha, J.; Jensen, A.; Vezzi, C.N.; Bailey, S.C.; De Boer, G.; Diehl, C.; Laurence, R.; Powers, C.W. Coordinated Unmanned Aircraft System (UAS) and Ground-Based Weather Measurements to Predict Lagrangian Coherent Structures (LCSs). Sensors 2018, 18, 4448. [CrossRef] [PubMed]

18. Lampert, A.; Altstädter, B.; Bärfuss, K.; Bretschneider, L.; Sandgaard, J.; Michaelis, J.; Lobitz, L.; Asmussen, M.; Damm, E.; Käthner, R. Unmanned Aerial Systems for Investigating the Polar Atmospheric Boundary Layer-Technical Challenges and Examples of Applications. Atmosphere 2020, 11, 416. [CrossRef]

19. Araujo, J.O.; Valente, J.; Kooistra, L.; Munniks, S.; Peters, R.J. Experimental Flight Patterns Evaluation for a UAV-Based Air Pollutant Sensor. Micromachines 2020, 11, 768. [CrossRef]

20. Chiliński, M.T.; Markowicz, K.M.; Kubicki, M. UAS as a Support for Atmospheric Aerosols Research: Case Study. Pure Appl. Geophys. 2018, 175, 3325-3342. [CrossRef]

21. Kobziar, L.N.; Pingree, M.R.; Watts, A.C.; Nelson, K.N.; Dreaden, T.J.; Ridout, M. Accessing the Life in Smoke: A New Application of Unmanned Aircraft Systems (UAS) to Sample Wildland Fire Bioaerosol Emissions and Their Environment. Fire 2019, 2, 56. [CrossRef]

22. Altstädter, B.; Platis, A.; Wehner, B.; Scholtz, A.; Wildmann, N.; Hermann, M.; Käthner, R.; Baars, H.; Bange, J.; Lampert, A. ALADINA-An Unmanned Research Aircraft for Observing Vertical and Horizontal Distributions of Ultrafine Particles within the Atmospheric Boundary Layer. Atmos. Meas. Tech. 2015, 8, 1627-1639. [CrossRef]

23. Altstädter, B.; Deetz, K.; Vogel, B.; Babić, K.; Dione, C.; Pacifico, F.; Jambert, C.; Ebus, F.; Bärfuss, K.; Pätzold, F. The Vertical Variability of Black Carbon Observed in the Atmospheric Boundary Layer during DACCIWA. Atmos. Chem. Phys. 2020, 20, 7911-7928. [CrossRef]

24. Crazzolara, C.; Ebner, M.; Platis, A.; Miranda, T.; Bange, J.; Junginger, A. A New Multicopter-Based Unmanned Aerial System for Pollen and Spores Collection in the Atmospheric Boundary Layer. Atmos. Meas. Tech. 2019, 12, 1581-1598. [CrossRef]

25. Bärfuss, K.; Pätzold, F.; Altstädter, B.; Kathe, E.; Nowak, S.; Bretschneider, L.; Bestmann, U.; Lampert, A. New Setup of the UAS ALADINA for Measuring Boundary Layer Properties, Atmospheric Particles and Solar Radiation. Atmosphere 2018, 9, 28. [CrossRef]

26. Leuenberger, D.; Haefele, A.; Omanovic, N.; Fengler, M.; Martucci, G.; Calpini, B.; Fuhrer, O.; Rossa, A. Improving High-Impact Numerical Weather Prediction with Lidar and Drone Observations. Bull. Am. Meteorol. Soc. 2020, 101, E1036-E1051. [CrossRef]

27. Wilgan, K.; Stauffer, R.; Meindl, M.; Geiger, A. Comparison of Tropospheric Parameters from Meteodrone Measurements with GNSS Estimates from Ground-Based Stations. Adv. Space Res. 2020, 66, 2812-2826. [CrossRef]

28. Lee, T.R.; Dumas, E.J.; Buban, M.S.; Baker, C.B.; Neuhaus, J.; Rogers, M.; Chappelle, N.; Marwine, C.; Swanson, M.; Amaral, C. Improved Sampling of the Atmospheric Boundary Layer Using Small Unmanned Aircraft Systems: Results from the Avon Park Experiment; National Oceanic and Atmospheric Administration: Washington, DC, USA, 2019.

29. Lauer, J.; Fengler, M. Meteodrones-Meteorological Planetary Boundary Layer Measurements by Vertical Drone Soundings. In Proceedings of the EGU General Assembly Conference Abstracts, Vienna, Austria, 23-28 April 2017; p. 2983.

30. Chilson, P.B.; Bell, T.M.; Brewster, K.A.; de Azevedo, G.B.H.; Carr, F.H.; Carson, K.; Doyle, W.; Fiebrich, C.A.; Greene, B.R.; Grimsley, J.L. Moving towards a Network of Autonomous UAS Atmospheric Profiling Stations for Observations in the Earth's Lower Atmosphere: The 3D Mesonet Concept. Sensors 2019, 19, 2720. [CrossRef] 
31. Bell, T.M.; Greene, B.R.; Klein, P.M.; Carney, M.; Chilson, P.B. Confronting the Boundary Layer Data Gap: Evaluating New and Existing Methodologies of Probing the Lower Atmosphere. Atmos. Meas. Tech. 2020, 13, 3855-3872. [CrossRef]

32. Moore, G.W.; Orozco, G.; Aparecido, L.M.; Miller, G.R. Upscaling Transpiration in Diverse Forests: Insights from a Tropical Premontane Site. Ecohydrology 2018, 11, e1920. [CrossRef]

33. Song, J.; Miller, G.R.; Cahill, A.T.; Aparecido, L.M.T.; Moore, G.W. Modeling Profiles of Micrometeorological Variables in a Tropical Premontane Rainforest Using Multi-Layered CLM (CLM-ML). J. Adv. Modeling Earth Syst. 2021, 13, e2020MS002259.

34. Andrews, R.S. The Temporal Variation of Vertical Micrometeorological Profiles in a Lower Montane Tropical Forest. Master's Thesis, Texas A \& M University, Bizzell St, TX, USA, 2016.

35. Aparecido, L.M.; Miller, G.R.; Cahill, A.T.; Moore, G.W. Leaf Surface Traits and Water Storage Retention Affect Photosynthetic Responses to Leaf Surface Wetness among Wet Tropical Forest and Semiarid Savanna Plants. Tree Physiol. 2017, 37, 1285-1300. [CrossRef] [PubMed]

36. Teale, N.G.; Mahan, H.; Bleakney, S.; Berger, A.; Shibley, N.; Frauenfeld, O.W.; Quiring, S.M.; Rapp, A.D.; Roark, E.B.; WashingtonAllen, R. Impacts of Vegetation and Precipitation on Throughfall Heterogeneity in a Tropical Pre-montane Transitional Cloud Forest. Biotropica 2014, 46, 667-676. [CrossRef]

37. Kindinger, J.G.; Davis, J.B.; Flocks, J.G. High-Resolution Single-Channel Seismic Reflection Surveys of Orange Lake and Other Selected Sites of North Central Florida; US Geological Survey, Center for Coastal Geology: Washington, DC, USA, 1994.

38. Pirkle, E.; Brooks, H. Origin and Hydrology of Orange Lake, Santa Fe Lake, and Levys Prairie Lakes of North-Central Peninsular Florida. J. Geol. 1959, 67, 302-317. [CrossRef]

39. Loucks, C.O.D.; Dinerstein, E.; Weakley, A.; Noss, R.; Stritholt, J.K. Wolfe Appalachian-Blue Ridge Forests. Available online: https:/ / www.worldwildlife.org/ecoregions/na0403 (accessed on 3 March 2019).

40. Prior, E.M.; Brumbelow, K.; Miller, G.R. Measurement of Above-canopy Meteorological Profiles Using Unmanned Aerial Systems. Hydrol. Process. 2019, 34, 865-867. [CrossRef]

41. FAA. Code of Federal Regulations (14 CFR) Part 107; FAA: Washington, DC, USA, 2016.

42. Dingman, S.L. Physical Hydrology, 3rd ed.; Waveland Press: Long Grove, IL, USA, 2015; ISBN 1-4786-2807-3.

43. Al-Jiboori, M.H.; Fei, H.U. Surface Roughness around a 325-m Meteorological Tower and Its Effect on Urban Turbulence. Adv. Atmos. Sci. 2005, 22, 595-605. [CrossRef]

44. Andreae, M.O.; Acevedo, O.C.; Araùjo, A.; Artaxo, P.; Barbosa, C.G.; Barbosa, H.; Brito, J.; Carbone, S.; Chi, X.; Cintra, B. The Amazon Tall Tower Observatory (ATTO): Overview of Pilot Measurements on Ecosystem Ecology, Meteorology, Trace Gases, and Aerosols. Atmos. Chem. Phys. 2015, 15, 10723-10776. [CrossRef] 